\title{
A 40 AÑOS DE ANÁLISIS FILOSÓFICO
}

Consejo Editorial

Con la presentación del segundo número del año 2020 se completa el cuadragésimo volumen de Análisis Filosófico. Con este motivo la Comisión Directiva de SADAF y el Consejo Editorial de la revista recuerdan su origen, permanencia y cambios operados en ella.

Frente a la actividad desarrollada en nuestra institución en la década de los 70 y principios de los 80 y dada la escasez de publicaciones filosóficas académicas en el mundo hispanoparlante, la Comisión Directiva de SADAF advirtió la necesidad de crear una publicación propia como órgano oficial de la sociedad en la que se pudieran volcar los resultados de investigaciones realizadas en su ámbito. Así surge Análisis Filosófico cuyo primer número -que solo contenía aportaciones locales- apareció en mayo de 1981. De ahí en más Análisis Filosófico inició su exitosa trayectoria que continúa hasta hoy. El propósito de crear esta publicación periódica tuvo una muy grata acogida que se puso de manifiesto en el beneplácito con que fue recibida por un importante número de destacados filósofos latinoamericanos y españoles.

A lo largo de la historia de SADAF se multiplicaron las reuniones académicas bajo la forma de coloquios, jornadas, congresos, workshops, seminarios y grupos de lectura; muchas de ellas se han visto reflejadas en las páginas de la revista.

Con el correr del tiempo no solo se difundieron trabajos surgidos en el espacio sadafiano sino que casi inmediatamente se fueron incorporando colaboraciones de colegas mexicanos, canadienses, españoles e inclusive norteamericanos, ya sea bajo la forma de artículos originalmente escritos en español, como así también traducciones de originales en inglés que de ese modo pudieron incluirse en el material bibliográfico utilizado en las esferas universitarias. No podemos dejar de mencionar en este sentido a Carlos Caorsi quien en 1982 cedió para los dos números del volumen II el conjunto de ocho trabajos dedicados a la obra de W. v. O. Quine, las respuestas del autor homenajeado a cada uno de ellos y una consideración final de todas las respuestas.

La permanencia de Análisis Filosófico a lo largo de tantos años, se debió, sin duda, al esfuerzo de todos los socios y en particular de aquellos que asumieron la tarea de participar en el Consejo Editorial. Con el objetivo claro de incorporarse al mundo de las revistas académicas de alto nivel, ese esfuerzo se encaminó fundamentalmente a adecuar nuestra revista a los más estrictos estándares internacionales (relativos 
a la periodicidad, sistema de evaluación, proporción de trabajos de miembros del consejo publicados en la revista, formato, etc.) lo que permitió su incorporación a las diferentes bases de datos que operan como parámetros de la evaluación de pares. Esta situación se pone de manifiesto, hoy, en la importante nómina de sitios que reconocen a Análisis Filosófico como revista académica filosófica internacional.

El logro que significó conquistar carácter internacional obedeció también y, en gran parte, a un cambio implementado por nuestra revista, que pasó de aceptar solo trabajos en español a admitir contribuciones en portugués y en inglés.

El paso de ser una publicación exclusivamente en papel a la ampliación implicada por la edición electrónica y su incorporación en el sistema de acceso abierto no comercial fue, también, determinante para comprender el lugar que hoy ocupa entre las revistas académicas.

Hoy la comunidad a la que Análisis Filosófico aspiraba a pertenecer se ha ampliado y no solo llega a nuestros colegas hispanoparlantes nativos americanos y europeos como fue inicialmente, sino también a otros espacios académicos luso y anglo parlantes.

A lo largo de estos 40 volúmenes se publicaron no solo dos números anuales sino también números temáticos especiales que en algunos casos recogen jornadas y simposios. Pueden recordarse, por ejemplo, volúmenes dedicados a la filosofía de la mente, a la filosofía del lenguaje, de la lógica, a temas de bioética y a la cuestión del canon filosófico. Se publicaron, también, algunos volúmenes y números de homenaje a destacados filósofos y a sus obras. Entre ellos mencionamos los dedicados a C. Alchourrón, E. Bulygin, C. Nino y R. Orayen.

En esta ocasión queremos, además, dedicar un párrafo especial al rol del Consejo Asesor para subrayar nuestro agradecimiento por su generosa colaboración y, sobre todo, por el aliento recibido. A todos ellos, iiimuchas gracias!!!

Aunque hubo consultas previas, en el número 2 del volumen VI de 1986, se publicó la nómina inicial del Consejo Asesor, constituido originalmente por: Carlos Alchourrón, Ernesto Garzón Valdez, Gregorio Klimovsky, Francisco Miró Quesada, João Paulo Monteiro, Thomas Nagel, Carlos Nino, Raúl Orayen, Mark Platts, Miguel Ángel Quintanilla, Fernando Salmerón, Thomas Moro Simpson, David Sobrevilla, Ernesto Sosa, Ernesto Villanueva y Georg von Wright. Gran parte de ellos ya no nos acompañan pero, sin duda, han dejado su impronta en nuestra revista. A lo largo de estas décadas se incorporaron nuevos nombres y esa lista habrá de incrementarse con los más destacados colegas que han creído y creen en este proyecto social editorial. 
Un agradecimiento, también, a todos aquellos filósofos y filósofas que han colaborado con Análisis Filosófico en la difícil y anónima tarea de asumir el rol de evaluadores de los trabajos presentados para su eventual publicación. 